Vol..5, No.2, 2019

Doi: https://doi.org/10.24198/cosmogov.v5i2.20060

http://jurnal.unpad.ac.id/cosmogov/index

\title{
IMPLEMENTASI KEBIJAKAN POPULIS DI PROVINSI DKI JAKARTA \\ (Studi Tentang Instruksi Gubernur Nomor 17 Tahun 2018 Terkait Penataan Kawasan Tanah Abang)
}

\author{
Choirunisa Agustin Hutari ${ }^{1}$ \\ Caroline Paskarina ${ }^{1}$ \\ ${ }^{\text {I}}$ Program Studi Ilmu Politik, Fakultas Ilmu Sosial dan Ilmu Politik Universitas Padjajaran \\ Jln. Raya Bandung Sumedang KM 21, Jatinangor 45363, Indonesia \\ Email: caroline.paskarina@unpad.ac.id
}

Submitted: January 04, 2019, Reviewed: October 18, 2019, Published: November 3, 2019

\begin{abstract}
ABSTRAK
Artikel ini membahas dimensi politik dari implementasi kebijakan, yang dianalisis dari kasus implementasi Instruksi Gubernur No. 17 Tahun 2018 terkait dengan penataan Kawasan Tanah Abang. Implementasi kebijakan ini menimbulkan kontroversi karena dinilai terlampau berpihak kepada pedagang kaki lima, sementara para pengguna jalan terabaikan akibat dari penutupan Jalan Jatibaru Raya yang selama ini digunakan sebagai jalan umum. Dengan menggunakan metode kualitatif, pengumpulan dan analisis data secara mendalam dilakukan untuk mengungkapkan bagaimana citra kepemimpinan populis diwujudkan melalui kebijakan ini dan bagaimana proses tawar-menawar politik mewarnai dinamika pelaksanaan kebijakan ini. Temuan penelitian menunjukan bahwa kebijakan penataan Kawasan Tanah Abang tidak berhasil memberikan manfaat kolektif bagi para aktor yang terkena dampak, sehingga memunculkan resistensi. Karakter kebijakan populis yang pragmatis menjadi kendala di dalam memberikan manfaat kolektif, sehingga agar keberpihakan pada publik dapat berdampak berkelanjutan, perlu melibatkan para aktor yang terkait untuk merancang kebijakan yang lebih komprehensif.
\end{abstract}

Kata kunci: implementasi kebijakan, kebijakan populis, manfaat kolektif

\begin{abstract}
This article discusses the political dimension of policy implementation, which is analyzed from the case of the implementation of Governor's Instruction No. 17 of 2018 related to the arrangement of Tanah Abang Area. The implementation of this policy caused controversy because it was considered to be too pro-street vendors, while road users and other traders in Tanah Abang were neglected due to the closure of Jalan Jatibaru Raya which had been used as a public road. Using qualitative methods, in-depth data collection and analysis is carried out to reveal a variety of interests contending and create strategies of actors to influence policy implementation, including to change populist policies that apparently do not provide collective benefits for actors. The research findings show that the policy to manage Tanah Abang area is a populist policy characterized by its pragmatic and partial character. These character becomes an obstacle in providing collective benefits, so that the pro-public intention can have a sustainable impact, it is necessary to involve relevant actors to design more comprehensive policies.
\end{abstract}

Keywords: policy implementation, populist policy, collective benefit 
Vol..5, No.2, 2019

Doi: https://doi.org/10.24198/cosmogov.v5i2.20060

http://jurnal.unpad.ac.id/cosmogov/index

\section{PENDAHULUAN}

Populisme telah menjadi kata kunci dalam dinamika politik di Indonesia, setidaknya dalam satu dekade terakhir. Kendati demikian, pemaknaannya cenderung terbatasi pada figur pemimpin politik yang dianggap merakyat. Padahal, konsep populisme sendiri memiliki banyak dimensi, bahkan di kalangan para pengkajinya pun masih berlangsung perdebatan tentang populisme dan variasi wujudnya (Canovan, 1999; Krouwel \& Amsterdam, 2015; Mudde \& Rovira Kaltwasser, 2017; Woods, 2014).

Secara konseptual, populisme dapat dianalisis dari empat perspektif (Paskarina, 2018). Keempat perspektif tersebut adalah populisme sebagai ideologi (De Raadt, Hollanders, \& Krouwel, 2004); populisme sebagai perlawanan terhadap struktur, rezim, atau gagasan yang mapan (Canovan, 1999); populisme sebagai gaya komunikasi politik (Grbeša \& Šalaj, 2016; Moffitt \& Tormey, 2014); dan perspektif yang keempat adalah populisme sebagai figur atau gerakan antikemapanan yang tumbuh untuk memobilisasi dukungan rakyat (Mietzner, 2015).

Diskursus populisme yang berkembang di Indonesia pun menunjukkan variasi kerangka analisis. Studi yang dilakukan Mietzner (2015) misalnya, berfokus pada kemunculan populisme teknokratis yang melekat pada gaya kepemimpinan Joko Widodo. Populisme teknokratis ini menjadi kekhasan Joko Widodo ketika berhadapan dengan Prabowo Subianto dalam Pemilihan Presiden 2014. Kendati Prabowo pun lekat dengan citra populis

karena kerap mengkritik kemapanan struktur ekonomi yang kapitalistik, tetapi kedua kandidat ini memunculkan bentuk populisme yang berbeda.

Kecenderungan mengaitkan populisme dengan figur atau gaya kepemimpinan mewarnai berbagai studi yang berkembang di Indonesia terutama pascapemilihan secara langsung (Aspinall, 2015; Hamid, 2014; Mietzner, 2009; Nurlinah, Darwin, \& Haryanto, 2017; Sulistiyanto, 2009). Studi-studi ini terutama melihat populisme yang muncul sebagai implikasi dari menguatnya politik berbasis figur dalam konteks pemilihan umum, baik di tingkat nasional maupun lokal.

Pada sisi yang berbeda, diskursus populisme di Indonesia juga memotret berkembangnya gerakan sosial yang menggunakan identitas sebagai bentuk perlawanan terhadap elit atau struktur yang dianggap mapan. Studi-studi yang dilakukan Hadiz (2014, 2016, 2018); Hadiz dan Robison (2017); Mudhoffir (2018); dan Perdana (2018) menjelaskan maraknya gerakan Islam di Indonesia pascareformasi sebagai bentuk kebangkitan populisme yang menggunakan Islam sebagai identitas politik untuk mengkritik praktik kekuasaan yang dianggap memarjinalkan identitas tersebut.

Berbagai
populisme tersebut memunculkan
kekhawatiran akan berdampak pada
menurunnya kualitas demokrasi di
Indonesia. Populisme sebagai gaya politik
dikhawatirkan mengarah pada
melemahnya pelembagaan sistem politik,
sedangkan populisme sebagai gerakan
politik identitas dikhawatirkan berdampak


Vol..5, No.2, 2019

Doi: https://doi.org/10.24198/cosmogov.v5i2.20060

http://jurnal.unpad.ac.id/cosmogov/index

pada politisasi dan fragmentasi massa (Aspinall \& Warburton, 2018; Eby Hara, 2018).

Artikel ini mencoba melihat populisme pada lingkup yang lebih mikro, yakni sebagai karakter kebijakan publik. Pemilihan langsung telah melahirkan banyak figur merakyat, yang berhasil memenangkan dukungan suara rakyat karena menawarkan janji-janji kampanye populis. Demikian pula yang terjadi dalam Pemilihan Gubernur DKI Jakarta 2017, di mana populisme tampak dari pertarungan citra para kandidatnya dan menguatnya politik identitas (Setijadi, 2017). Artikel ini akan lebih berfokus pada penerjemahan janji-janji kampanye pasangan terpilih (Anies Baswedan dan Sandiaga Uno) ke dalam kebijakan publik setelah keduanya memerintah. Kebijakan populis tampaknya tidak menjadi kajian tersendiri dari populisme, tetapi menjadi bagian yang dibahas dalam dimensi populisme sebagai strategi politik, khususnya dalam pengelolaan sumber daya (Dinc, 2016; Sachs, 1990). Sachs (1990) tidak secara tegas mendefinisikan kebijakan populis, tetapi lebih menggambarkannya sebagai tipe atau karakter pembuatan kebijakan yang bersifat makro dan dibuat untuk menyelesaikan persoalan dalam jangka pendek.

Kecenderungan pragmatis dari kebijakan populis juga ditegaskan oleh Mudde (2004), bahwa kebijakan populis merupakan opportunistic policies with the aim of (quickly) pleasing the people/voters (Mudde, 2004). Definisi tersebt menunjukkan bahwa kebijakan populis seringkali lahir dari konteks politik yang bersifat oportunistik, untuk mencapai tujuan jangka pendek, yakni memuaskan rakyat atau pemilih.

Artikel ini akan berfokus pada salahsatu kebijakan populis yang berkenaan dengan penataan pedagang kaki lima (PKL) di DKI Jakarta. Terbitnya kebijakan penataan Kawasan Tanah Abang sebagai kebijakan populis cukup menimbulkan kontroversi. Kontroversi ini muncul karena Instruksi Gubernur No. 17 Tahun 2018 tentang Penataan Kawasan Tanah Abang, yang dikeluarkan oleh Gubernur Anies Baswedan berbeda dengan Peraturan Gubernur sebelumnya, yakni Peraturan Gubernur No. 41 Tahun 2014 tentang Pengembangan Kawasan Sentra Primer Tanah Abang, yang menunjuk P.D. Pembangunan Sarana Jaya untuk melakukan pembebasan lahan atau bekerja sama dengan pihak swasta atau pihak terkait yang memang memiliki lahan-lahan di Kawasan Tanah Abang.

Instruksi Gubernur tahun 2018 justru menginstruksikan Walikota, Dinas Koperasi Usaha Kecil dan Menengah, Dinas Perhubungan, Dinas Lingkungan Hidup, Dinas Bina Marga, Satuan Polisi Pamong Praja, dan P.T. Transjakarta untuk saling berkoordinasi untuk mengoptimalkan ketertiban di Jalan Jatibaru Raya Tanah Abang. Ketertiban yang dimaksud adalah merujuk pada penutupan Jalan Jatibaru Raya dari pukul 08.00 sampai dengan $18.00 \mathrm{WIB}$, yang dilakukan sejak tanggal 22 Desember 2017. Penutupan Jalan Jatibaru Raya tersebut bertujuan untuk menjadikan sisi timur jalan sebagai lahan untuk para Pedagang Kaki Lima berjualan di dalam tenda, dan satu 
Vol..5, No.2, 2019

Doi: https://doi.org/10.24198/cosmogov.v5i2.20060

http://jurnal.unpad.ac.id/cosmogov/index

ruas jalan lainya untuk jalur Busway Transjakarta yang beroperasi secara gratis agar penumpang yang keluar dari Stasiun Tanah Abang dapat diangkut secara tertib hingga keluar Kawasan Tanah Abang.

Pada satu sisi, banyak dukungan yang diterima oleh Anies dan Sandi khususnya dari kalangan PKL di kawasan Tanah Abang karena kebijakan ini melegitimasi keberadaan mereka dengan mengizinkan mereka berjualan di kawasan yang semula bukan diperuntukan bagi PKL. Tapi, juga menuai kritik yang cukup tajam, karena kontraproduktif dengan grand design kebijakan pemerintah sebelumnya yang mencoba mengembalikan PKL untuk berjualan di dalam pasar, bahkan juga dinilai bertentangan dengan Undang-Undang Nomor 22 Tahun 2009 tentang Lalu Lintas dan Angkutan Jalan, Peraturan Pemerintah Nomor 34 Tahun 2006 tentang Jalan, dan Peraturan Daerah DKI Jakarta Nomor 8 Tahun 2007 tentang Ketertiban Umum. Selain alih fungsi jalan, Pemerintah Provinsi DKI Jakarta yang mengabaikan hak pejalan kaki atau pedestrian dalam menggunakan fasilitas trotoar yang melanggar Peraturan Daerah Nomor 5 Tahun 2014 tentang Transportasi.

Kontroversi yang muncul dalam implementasi Instruksi Gubernur tentang Penataan Kawasan Tanah Abang tersebut menjadi ilustrasi yang menarik untuk dianalisis dari perspektif kebijakan populis, terutama untuk mengungkapkan dinamika kuasa yang berlangsung di dalam implementasi Instruksi Gubernur tentang Penataan Kawasan Tanah Abang sebagai suatu kebijakan populis. Dinamika kuasa ini dipetakan melalui ragam kepentingan para aktor yang terlibat dalam implementasi kebijakan serta strategi yang digunakan untuk memperjuangkan kepentingannya tersebut.

\section{METODE PENELITIAN}

Studi ini ingin mengungkapkan dinamika kuasa yang mewarnai konteks implementasi kebijakan populis, dengan asumsi bahwa implementasi kebijakan bukan semata proses linear atau administratif (Grindle, 2017). Untuk mengungkapkan dimensi politik tersebut, studi ini menggunakan pendekatan kualitatif di dalam pengumpulan, pengolahan, dan analisis datanya, agar pembahasan temuan dapat disajikan dengan lebih mendalam.

Pengumpulan data dilakukan melalui wawancara mendalam dengan para aktor yang terlibat di dalam implementasi Instruksi Gubernur, yakni Ketua Tim Gubernur Untuk Percepatan Pembangunan Pemprov DKI Jakarta, Ombudsman DKI Jakarta, dan Pedagang Kaki Lima Kawasan Tanah Abang. Wawancara secara semi terstruktur dilakukan untuk menggali informasi tentang konteks lahirnya kebijakan serta dinamika yang berlangsung selama pelaksanaan kebijakan. Selain itu, data yang diperoleh melalui wawancara juga digunakan untuk memvalidasi temuan yang diperoleh melalui studi terhadap peraturan-peraturan yang berkaitan dengan penataan Kawasan Tanah Abang.

Pengolahan data dilakukan dengan mengikuti tahapan analisis data yang dikemukakan oleh Miles dan Huberman (2012), yakni pengumpulan data, reduksi 
Vol..5, No.2, 2019

Doi: https://doi.org/10.24198/cosmogov.v5i2.20060

http://jurnal.unpad.ac.id/cosmogov/index

data, dan penyajian data. Data yang dikumpulkan selanjutnya diolah berdasarkan kategori yang disusun berdasarkan konsep implementasi kebijakan dari Grindle (2017), yakni kekuasaan, kepentingan, dan strategi dari para aktor yang terlibat; karakteristik institusi dan rezim; serta kepatuhan dan reponsivitas. Hasil analisis data berdasarkan ketiga kategori ini selanjutnya disajikan sebagai pembabakan dalam pembahasan.

\section{HASIL DAN PEMBAHASAN}

Kekuasaan, kepentingan, dan strategi para aktor

Implementasi Instruksi Gubernur No. 17 Tahun 2018 tentang Penataan Kawasan Tanah Abang memuat kepentingan yang beragam. Bagi Pemerintah Provinsi DKI Jakarta, kepentingannya adalah mengoptimalkan penataan Kawasan Tanah Abang agar ketidakteraturan yang selama ini mewarnai kawasan tersebut dapat diatasi. Dengan demikian, okupasi ruang publik di Kawasan Tanah Abang dapat diatur, sehingga tidak merugikan publik. Penertiban dan penataan Kawasan Tanah Abang diharapkan dapat mencapai kondisi yang diinginkan oleh Pemerintah Provinsi DKI Jakarta, yakni situasi kondusif yang terjaga, terkoneksinya antarmoda transportasi, serta menjadi lingkungan yang nyaman. Untuk mewujudkan hal itu, Pemerintah Provinsi DKI Jakarta memutuskan menutup Jalan Jatibaru Raya sebagai strategi untuk merebut ruang-ruang publik yang semula dikuasai oleh PKL.
Strategi tersebut di sisi lain, menimbulkan persoalan tersendiri karena berdampak pada kepentingan aktor lain, yakni para pedagang di Pasar Blok G. Pedagang ini merupakan PKL yang sebelumnya direlokasi oleh Gubernur Joko Widodo pada tahun 2012 karena fungsi awal dibangunnya Pasar Blok G sendiri adalah untuk menampung seluruh PKL ke dalam gedung di Pusat Perdagangan Pasar Tanah Abang.

Akibat pemberlakuan Instruksi Gubernur yang baru, para pedagang Pasar Blok $G$ mengalami kerugian berupa menurunnya omzet penjualan, sekitar 50$60 \%$ (hasil wawancara dengan S, PKL di Pasar Blok G). Sebaliknya, dengan diizinkannya Jalan Jatibaru Raya dijadikan sebagai tempat berjualan, para calon pembeli lebih tertarik untuk bertransaksi dengan pedagang di Jalan Jatibaru Raya karena lebih mudah aksesnya ketimbang harus masuk ke Pasar Blok G.

Untuk mempertahankan kepentingannya, para pedagang Pasar Blok $G$ berupaya beraudiensi dengan Pemerintah Provinsi DKI Jakarta untuk menyampaikan keluhannya. Tercatat sebanyak 4 (empat) kali para pedagang Pasar Blok $\mathrm{G}$ berupaya menemui Pemerintah Provinsi DKI Jakarta dan DPRD Provinsi DKI Jakarta, yakni pada bulan Desember 2017, 11 Januari 2018, 22 Januari 2018, dan 3 Februari 2018. Karena tidak ada tanggapan seperti yang diharapkan dari pihak pemerintah dan DPRD, para pedagang Pasar Blok G kemudian berupaya menyampaikan aspirasinya kepada Ombusdman DKI Jakarta, yakni lembaga yang bertugas 
Vol..5, No.2, 2019

Doi: https://doi.org/10.24198/cosmogov.v5i2.20060

http://jurnal.unpad.ac.id/cosmogov/index

memantau kinerja pelayanan publik yang disediakan oleh pemerintah.

Ombusdman kemudian melakukan investigasi untuk menindaklanjuti pengaduan yang masuk. Ada 3 (tiga) aspek yang menjadi objek pemeriksaan, yakni terkait alih fungsi jalan; manajemen rekayasa lalu lintas; dan pengelolaan Pasar Tanah Abang. Berdasarkan hasil pemeriksaan, Ombudsman pun menyatakan bahwa ada tindakan maladministrasi dalam pelaksanaan Instruksi Gubernur No. 17 Tahun 2018. Tindakan maladministrasi tersebut berkaitan dengan penggunaan diskresi oleh Gubernur DKI Jakarta dalam penataan Kawasan Tanah Abang yang merupakan bentuk pengabaian kewajiban hukum karena telah terdapat ketentuan peraturan perundang-undangan yang mengatur mengenai tata ruang dan tidak sesuai dengan tujuan penggunaan diskresi.

Berdasarkan regulasi tata ruang Kawasan Tanah Abang yang diatur dalam Pasal 98 ayat (1) Peraturan Daerah Nomor 1 Tahun 2012, Sentra Primer Tanah Abang ditetapkan sebagai program utama perwujudan struktur ruang provinsi dengan waktu pelaksanaan selama 10 tahun pertama (2 kali masa pelaksanaan Rencana Jangka Menengah). Konsekuensinya, Pemerintah Provinsi DKI Jakarta seyogianya melaksanakan regulasi tersebut dan bukan menutup Jalan Jatibaru Raya untuk dijadikan lokasi berdagang PKL.

Benturan kepentingan muncul ketika Pemerintah Provinsi DKI Jakarta menggunakan diskresi sebagai legitimasi di dalam pengambilan kebijakan penutupan Jalan Jatibaru Raya. Berdasarkan UU No.
30 Tahun 2014 tentang Administrasi Pemerintahan, diskresi adalah keputusan dan/atau tindakan yang ditetapkan dan/atau dilakukan oleh Pejabat Pemerintahan untuk mengatasi persoalan konkret yang dihadapi dalam penyelenggaraan pemerintahan, dalam hal peraturan perundang-undangan yang memberikan pilihan, tidak mengatur, tidak lengkap, atau tidak jelas, dan/atau adanya stagnasi pemerintahan. Tetapi, UU ini pun menegaskan bahwa di dalam penggunaan diskresi, Pejabat Pemerintahan tidak boleh bertentangan dengan ketentuan peraturan perundang-undangan. Karena itu, keputusan Pemerintah Provinsi DKI Jakarta untuk menutup Jalan Jatibaru Raya dan menggunakannya untuk kepentingan lain, tidak dapat dibenarkan dengan dasar penggunaan diskresi.

Hal inilah yang menjadi dasar bagi Ombudsman untuk menyatakan bahwa Instruksi Gubernur tersebut merupakan praktik maladministrasi dan selanjutnya menyampaikan agar Pemerintah Provinsi DKI Jakarta segera melakukan perbaikan atau langkah korektif, terutama mengembalikan fungsi Jalan Jatibaru Raya Tanah Abang sesuai peruntukannya untuk lalu lintas angkutan jalan dan pedestrian untuk pejalan kaki. Ombudsman menetapkan masa transisi selambatlambatnya 60 (enam puluh) hari dengan melibatkan partisipasi semua pemangku kepentingan, sesuai dengan tugas dan fungsinya masing-masing di dalam memperbaiki pelaksanaan Instruksi Gubernur tersebut.

Langkah yang diambil Ombudsman tersebut merupakan upaya untuk melindungi kepentingan masyarakat, 
Vol..5, No.2, 2019

Doi: https://doi.org/10.24198/cosmogov.v5i2.20060

http://jurnal.unpad.ac.id/cosmogov/index

sekaligus menempatkan kembali peruntukan Jalan Jatibaru Raya sesuai dengan ketentuan peraturan perundangundangan yang lebih khusus. Kendati Instruksi Gubernur tersebut lahir sebagai bentuk kebijakan populis yang mencerminkan keberpihakan kepada para PKL, tetapi keputusan yang diambil Ombudsman pun pada dasarnya merupakan keputusan demi kepentingan publik yang lebih luas. Dalam konteks ini, tampak bahwa kekuasaan dan kepentingan para aktor yang terlibat saling bertarung untuk memperoleh pengakuan secara normatif oleh lembaga yang memiliki otoritas. Konsep populisme sendiri menekankan pada keberpihakan kepada publik sebagai lawan terhadap kepentingan elitis (Canovan, 1999). Dalam kasus implementasi Instruksi Gubernur tentang Penataan Kawasan Tanah Abang, tampak bahwa kebijakan yang dibuat oleh elit pemerintah atas nama keberpihakan kepada PKL justru mendapat resistensi dari para pedagang Pasar Blok $\mathrm{G}$ dan dari para pengguna jalan yang kepentingannya terganggu. Pemerintah menggunakan diskresi sebagai dasar legitimasi tindakannya, sebaliknya para pedagang Pasar Blok G pun berupaya memperjuangkan kepentingannya dengan menggunakan lembaga lain yang memiliki otoritas yang sebanding dengan pemerintah.

\section{Karakteristik institusi dan rezim}

Konsistensi sikap Pemerintah Provinsi DKI Jakarta di dalam implementasi Instruksi Gubernur dapat dilihat dari komitmen dalam melaksanakan penutupan Jalan Jatibaru Raya. Bagi Pemerintah Provinsi DKI Jakarta, penutupan Jalan Jatibaru Raya dianggap sebagai cara paling tepat dan cepat untuk menanggulangi permasalahan di Kawasan Tanah Abang, meskipun kebijakan tersebut berbenturan dengan peraturan perundangundangan lainnya.

Dalam wawancara dengan informan dari Pemerintah Provinsi DKI Jakarta, terungkap bahwa pertimbangan utama bagi Pemerintah Provinsi di dalam melaksanakan penutupan Jalan Jatibaru Raya adalah memastikan bahwa layanan perpindahan penumpang dapat berlangsung dengan lebih nyaman dan ketertiban di stasiun tetap terjaga (wawancara dengan HP, aparat Pemerintah Provinsi DKI Jakarta).

Informan juga menegaskan bahwa bagi Pemerintah Provinsi DKI Jakarta, manfaat yang dihasilkan dari implementasi Instruksi Gubernur itu adalah bersihnya ruang publik di sekitar Stasiun Tanah Abang, yang semula diokupasi oleh para PKL. Dengan menutup Jalan Jatibaru Raya, penumpang Transjakarta yang turun di Stasiun Tanah Abang tidak terganggu lagi dengan para PKL. Sebaliknya, para PKL diberi kesempatan berjualan di tendatenda yang disediakan Pemerintah Provinsi di Jalan Jatibaru Raya yang ditutup. Para PKL ini juga akan merasa lebih nyaman berdagang tanpa khawatir ditertibkan oleh Petugas Satuan Polisi Pamong Praja.

Pernyataan di atas menunjukkan bahwa dasar pengambilan keputusan untuk menutup Jalan Jatibaru Raya adalah untuk kenyamanan sarana transportasi, yang dipandang sebagai kepentingan publik 
Vol..5, No.2. 2019

Doi: https://doi.org/10.24198/cosmogov.v5i2.20060

http://jurnal.unpad.ac.id/cosmogov/index

yang lebih luas ketimbang kepentingan para pedagang di Kawasan Pasar Tanah Abang. Ini jelas menunjukkan karakter kebijakan populis yang berorientasi pada kepentingan publik. Menurut Grindle (2017), salahsatu faktor keberhasilan implementasi kebijakan adalah kemampuannya memberi manfaat kolektif kepada banyak pihak.

Tetapi, pada sisi lain, pilihan untuk berpihak pada kepentingan pengguna stasiun justru menyebabkan benturan dengan kepentingan lain, yakni keberlangsungan perdagangan di kawasan pasar Tanah Abang dan kepentingan penataan ruang yang lebih luas. Implementasi kebijakan ini menimbulkan persoalan lain yang berkaitan erat dengan manajemen rekayasa lalu lintas, yakni terjadinya kemacetan di beberapa titik di Kawasan Tanah Abang. Persoalan ini muncul karena kurangnya koordinasi yang dilakukan dengan Polda Metro Jaya yang memiliki kewenangan di dalam rekayasa lalu lintas. Manajemen rekayasa lalu lintas yang telah dirancang pun tidak melibatkan pihak-pihak terkait, seperti Forum Lalu Lintas dan Angkutan Jalan, sehinigga memunculkan resistensi dari sejumlah pengemudi angkutan kota. Hal ini juga menegaskan karakter kebijakan populis yang cenderung pragmatis, yakni menyelesaikan persoalan untuk jangka pendek (Mudde, 2004; Sachs, 1990), tanpa mempersiapkan upaya-upaya yang lebih komprehensif untuk mengatasi dampak yang ditimbulkan dari implementasi kebijakan tersebut bagi pihak-pihak lainnya.

\section{Kepatuhan dan reponsivitas}

Kepatuhan dan responsivitas Pemerintah DKI Jakarta sebagai pelaksana kebijakan, dilihat dari bagaimana Pemerintah Provinsi merespon persoalan yang muncul setelah implementasi dilaksanakan. Tuntutan yang disampaikan oleh berbagai pihak, khususnya Ombudsman, berdampak pada implementasi kebijakan. Pemerintah Provinsi menilai bahwa implementasi kebijakan tersebut sesuai dengan rancangan yang telah ditentukan sejak awal dan berhasil mencapai tujuan, yakni menertibkan Jalan Jatibaru Raya. Tetapi, Pemerintah Provinsi juga tidak dapat mengabaikan tuntutan dan resistensi yang muncul terkait pelaksanaan kebijakan tersebut.

Melalui proses yang cukup panjang, Pemerintah Provinsi DKI Jakarta kemudian merespon tuntutan publik dan akhirnya memutuskan untuk menghentikan kebijakan penutupan Jalan Jatibaru Raya Tanah Abang. Untuk mewadahi kepentingan penataan PKL, Pemerintah Provinsi kemudian mengembangkan kebijakan baru, yakni membangun Jembatan Penyeberangan Multiguna (JPM) atau skybridge di sepanjang Jalan Jatibaru Raya. Skybridge sepanjang 386,4 meter dengan lebar 12,6 meter ini nantinya akan menghubungkan Stasiun Tanah Abang dengan Blok G. Kebijakan yang baru ini diharapkan dapat mengakomodasi kepentingan pihak-pihak yang selama ini menolak pelaksanaan Instruksi Gubernur.

Pembangunan skybridge merupakan keputusan yang lahir sebagai respon terhadap kebijakan populis yang 
Vol..5, No.2, 2019

Doi: https://doi.org/10.24198/cosmogov.v5i2.20060

http://jurnal.unpad.ac.id/cosmogov/index

cenderung pragmatis di dalam menyelesaikan permasalahan di Kawasan Tanah Abang. Berbeda dengan kebijakan sebelumnya, pembangunan skybridge dapat mengakomodasi kepentingan Pemerintah Provinsi DKI Jakarta untuk memberikan kenyamanan bagi arus pelaku komuter yang menggunakan Stasiun Tanah Abang. Selain itu, para pelaku komuter yang diindikasi sebagai impulse buyer juga dapat tersalurkan kepentingannya karena skybridge ini juga nantinya berfungsi sebagai sarana berjualan bagi PKL. Dengan demikian, kepentingan para PKL secara ekonomis juga terpenuhi. Sementara Jalan Jatibaru Raya akan dikembalikan fungsinya sesuai dengan peruntukannya sebagai sarana transportasi.

Hal di atas menunjukkan bahwa implementasi kebijakan populis memasuki fase yang lebih terlembaga sebagai konsekuensi dari respon yang diberikan oleh para aktor yang terlibat. Pada satu sisi, ini menegaskan asumsi keterbatasan kebijakan populis dalam hal kontinuitas karena kecenderungannya untuk pragmatis dan parsial (Mudde, 2004; Sachs, 1990), tetapi pada sisi lain, juga memberi peluang bagi munculnya kompromi baru yang menandai terbentuknya konteks kebijakan baru (Grindle, 2017) yang menambah dinamis implementasi kebijakan.

\section{SIMPULAN}

Kebijakan penataan Kawasan Tanah Abang, khususnya dalam bentuk Instruksi Gubernur No. 17 Tahun 2018, merupakan kebijakan populis yang lahir dari keinginan untuk mewujudkan kepentingan publik, yakni kenyamanan bagi para pengguna Jalan Jatibaru Raya dan menyediakan tempat berjualan yang teratur bagi para pedagang kaki lima. Tetapi, kebijakan ini kemudian menimbulkan resistensi dari pihak-pihak lain yang kepentingannya terganggu. Resistensi ini muncul karena manfaat yang dihasilkan dari implementasi kebijakan populis tidak bersifat kolektif. Ruang publik yang semula diokupasi oleh para PKL dapat dikelola kembali oleh Pemerintah Provinsi DKI Jakarta, tetapi timbul kemacetan di lingkar luar Kawasan Tanah Abang akibat dari manajemen rekayasa lalu lintas yang kurang terkoordinasi dengan kepolisian. Dalam relasi antarpedagang kaki lima, juga muncul situasi yang tidak kondusif karena para pedagang di Pasar Blok G justru mengalami kerugian akibat keberadaan para PKL di Jalan Jatibaru Raya.

Kendati pada awalnya Pemerintah Provinsi DKI Jakarta mengabaikan resistensi tersebut, tetapi pada akhirnya Pemerintah Provinsi merespon dengan menghentikan kebijakan populis yang pragmatis tersebut. Perubahan keputusan tersebut menunjukkan bahwa dinamika politik menjadi faktor penting yang mempengaruhi konteks pelaksanaan kebijakan, sehingga dalam prosesnya dapat mempengaruhi pelaksana bahkan menimbulkan perubahan yang mengarah pada kebijakan yang lebih komprehensif.

\section{DAFTAR PUSTAKA}

Aspinall, E. (2015). Oligarchic Populism: Prabowo Subianto's Challenge to Indonesian Democracy. Indonesia, (99), https://doi.org/10.5728/indonesia.9 9.0001 
Vol..5, No.2, 2019

Doi: https://doi.org/10.24198/cosmogov.v5i2.20060

http://jurnal.unpad.ac.id/cosmogov/index

Aspinall, E., \& Warburton, E. (2018). Indonesia: The Dangers of Democratic Regression. In Advances in Social Science, Education and Humanities Research (ASSEHR). Atlantis Press. https://doi.org/10.2991/icsps17.2018.1

Canovan, M. (1999). Trust the People! Populism and the Two Faces of Democracy. Political Studies, XLVII, 2-16.

De Raadt, J., Hollanders, D., \& Krouwel, A. (2004). Varieties of Populism: An Analysis of the Programmatic Character of Six European Parties. Political Science.

Dinc, P. (2016). A report on Mapping Populism.

Eby Hara, A. (2018). Populism in Indonesia and its Threats to Democracy, 129(Icsps 2017), 106111. https://doi.org/10.2991/icsps17.2018.23

Grbeša, M., \& Šalaj, B. (2016). Textual Analysis of Populist Discourse in 2014/2015 Presidential Election in Croatia. Contemporary Southeastern Europe, 3(1), 106127. Retrieved from http://www.suedosteuropa.unigraz.at/cse/en/grbesa_salaj\% $\% \mathrm{Cnw}$ ww.contemporarysee.org

Grindle, M. S. (2017). Politics and policy implementation in the third world. Princeton, New Jersey: Princeton University Press. https://doi.org/10.2307/2619175

Hadiz, V. R. (2014). A New Islamic Populism and the Contradictions of Development. Journal of Contemporary Asia, 44(1). https://doi.org/10.1080/00472336.2 013.832790

Hadiz, V. R. (2016). Islamic populism in Indonesia and the Middle East. Islamic Populism in Indonesia and the Middle East.

Hadiz, V. R. (2018). Imagine All the People? Mobilising Islamic Populism for Right-Wing Politics in Indonesia. Journal of
Contemporary Asia, 48(4). https://doi.org/10.1080/00472336.2 018.1433225

Hadiz, V. R., \& Robison, R. (2017). Competing populisms in postauthoritarian Indonesia. International Political Science Review, 38(4), 488-502. https://doi.org/10.1177/019251211 7697475

Hamid, A. (2014). Jokowi's Populism in the 2012 Jakarta Gubernatorial Election. Journal of Current Southeast Asian Affairs, 33(1), 85109. Retrieved from http://journals.sub.unihamburg.de/giga/jsaa/article/view Article/738

Krouwel, A., \& Amsterdam, V. U. (2015). Varieties of Populism: An Analysis of the Programmatic Character of Six European Parties Department of Political Science Varieties of Populism: An Analysis of the Programmatic Character of Six European Parties Jasper de Raadt , David Hollanders , André , (January 2004).

Mariana, A., \& Nurmilah, M. (2013). Inilah Pesan Penting di Balik Berkah dan Manfaat Silaturahmi. Jakarta: Ruang Kata.

Mietzner, M. (2009). Indonesia's 2009 Elections: Populism, Dynasties and the Consolidation of the Party System. Sydney: Lowy Institute for International Policy, (May), 1-24.

Mietzner, M. (2015). Reinventing Asian Populism: Jokowi's Rise, Democracy, and Political Contestation in Indonesia. Policy Studies (15471349). Retrieved from

http://search.ebscohost.com/login.a spx?direct $=$ true $\& d b=a 9 h \& A N=10$ 2181521\&site $=$ ehostlive\&scope $=$ site

Miles, M. B., \& Huberman, M. A. (2012). Analisis Data Kualitatif: Buku Sumber Tentang Metode-Metode Baru. Universitas Indonesia_UI Press. 
Vol..5, No.2, 2019

Doi: https://doi.org/10.24198/cosmogov.v5i2.20060

http://jurnal.unpad.ac.id/cosmogov/index

Moffitt, B., \& Tormey, S. (2014). Rethinking populism: Politics, mediatisation and political style. Political Studies, 62(2), 381-397. https://doi.org/10.1111/14679248.12032

Mudde, C. (2004). The Populist Zeitgeist. Government and Opposition, 39(4), 541-563.

Mudde, C., \& Rovira Kaltwasser, C. (2017). Populism: A Very Short Introduction. Very Short Introductions, 131. https://doi.org/10.1093/actrade/978 0190234874.001.0001

Mudhoffir, A. M. (2018, January 23). Aliansi Populis Islam yang Terfragmentasi. Indoprogress.

Nurlinah, Darwin, R. L., \& Haryanto. (2017). Incumbency Disadvantages: LOcal Election and Populism in Indonesia. In Advances in Social Science, Education and Humanities Research (ASSEHR) (Vol. 129, pp. 190-193).

Paskarina, C. (2018). Textual Analysis of Populist Discourse in Development Policy of Bandung City. In Advances in Social Science, Education and Humanities Research. https://doi.org/10.2991/icsps17.2018.28
Perdana, A. A. (2018). Kebangkitan Populisme Islam di Indonesia: Sebuah Perdebatan. (C. H. Pontoh, Ed.). Jakarta: IndoProgress.

Sachs, J. (1990). Social Conflict and Populist Policies in Latin America. In Labour Relations and Economic Performance. https://doi.org/10.1007/978-1-34911562-4_6

Setijadi, C. (2017). Ahok's Downfall and the Rise of Islamist Populism in Indonesia, (38), 1-9. Retrieved from

https://www.iseas.edu.sg/images/p df/ISEAS_Perspective_2017_38.p df

Sulistiyanto, P. (2009). Pilkada in Bantul District: Incumbant, Populism and Decline of Royal Power. In M. Erb \& P. Sulistiyanto (Eds.), Deepening Democracy in Indonesia: Direct Election for Local Leader (Pilkada) (pp. 190210). Singapore: ISEAS Publishing.

Woods, D. (2014). The Many Faces of Populism: Diverse but not Disparate. Research in Political Sociology, 22, 1-25. https://doi.org/10.1108/s0895993520140000022014 